\title{
LA INSPECCIÓN ESCOLAR EN IBEROAMÉRICA: EL CASO DE CHILE
}

\section{School Inspection in Ibero-America: the case of Chile}

\author{
Adolfo I. GonZÁLEz BRITO \\ Universidad de La Frontera, Temuco, Chile
}

Correo-e: adolfo.gonzalez@ufrontera.cl

Recepción: 5 de noviembre de 2018

Envío a informantes: Io de noviembre de 2018

Aceptación definitiva: 3 de enero de 2019

Resumen: En Chile, la Inspección Escolar se conoce como Supervisión Educativa y tiene, en general, el mismo carácter que en otros países de Iberoamérica salvo algunas diferencias sustanciales en orden a sus roles y funciones que han sido en el tiempo bastante dinámicos; pero los inspectores, en adelante supervisores, son funcionarios de Estado de nivel intermedio. Este artículo da cuenta de la evolución histórica que ha tenido la Supervisión Educativa en Chile desde el año 1965 hasta la actualidad en algunos aspectos específicos. Principalmente, en orden al paradigma que sustenta su desempeño en orden a la política educativa y, más específicamente, en orden a sus roles y funciones en el sistema escolar.

Palabras Clave: Supervisión; Inspección escolar; política educativa; Iberoamérica; Chile; sistema educativo.

Aвstract: In Chile, School Inspection is known as Educational Supervision and, in general, it has the same character as other Latin American countries, except for some differences related to their roles that have been dynamic over the time; the inspectors, called Supervisors, are State officials at an intermediate level. This article gives an overview of the historical evolution of Educational Supervision in Chile since 1965 to the present. Mainly in order to the paradigm that sustains its performance in order to educational policy and, specifically, in order to their roles in the school system.

KEY wORDs: Supervision; School Inspection; educational policy; Ibero-America; Chile; educational system. 


\section{Antecedentes}

$\mathrm{E}$ L AÑo i965 MARCA UN Hito HistóRICO EN Chile con el advenimiento del Gobierno de Eduardo Frei Montalva (1965-1970), quien inició una «Revolución en Libertad», según rezaba su eslogan y que aglutinó un gran apoyo ciudadano y una juventud idealista y con aspiraciones de justicia social en una sociedad de clases marcada por privilegios y segregación social. De hecho, la educación es un eje destacado en el Programa de Gobierno, de inspiración demócrata cristiana. En la época y todavía hasta mucho después, el principal problema era de cobertura escolar, había escuelas que colgaban un anuncio en sus puertas que rezaba literalmente: «No hay vacantes». El presidente Frei Montalva hizo suya la aspiración de «todos los niños a la escuela» y creó programas de formación de profesores 'exprés' para enfrentar las necesidades de creación de escuelas. En este contexto, se requirió de un protagonismo activo de los supervisores a fin de monitorear -controlar- tanto la formación 'exprés' como las propias de su tarea habitual que era, en esa época: tareas inspectoras, fiscalizar documentación propia de escuelas y docentes, aspectos curriculares, didácticos y evaluativos, dentro de una amplia gama de funciones académicas, administrativas y financieras, etc. La tarea emprendida fue muy exitosa en incremento de la matrícula y, consecuentemente, mejora notable de la cobertura escolar.

Durante el siguiente Gobierno del Presidente Salvador Allende Gossens (19701973) se profundizaron las reformas del Gobierno anterior y se proyectó una nueva reforma educacional: La Escuela Nacional Unificada (ENU), que quedó finalmente solo un proyecto pues no alcanzó a plasmarse debido a la intervención militar del iI de septiembre de i973. La naturaleza del proyecto ENU buscaba mejorar la educación pública de manera radical desde la temprana infancia hasta la educación superior. Una vez establecida la Dictadura Militar (1973-1990) mediante el uso de la fuerza, la interdicción del parlamento y la prohibición de reuniones y actividades políticas, una fuerte y cruel represión a los funcionarios del Gobierno del presidente S. Allende, las relegaciones y exilios luego de la criba de la tortura y muerte a los cuadros más cercanos al presidente muerto. A la sazón, y en el periodo inmediatamente posterior, los supervisores, como agentes del Estado, seguían con las mismas funciones en orden a la fiscalización y control de índole ideológica, administrativa y financiera, con gran poder y peso específico en el sistema escolar. Dejar claro que las tareas inspectoras de índole financiero-económica quedaban en manos de otro funcionario adjunto denominado «Inspector de subvenciones». Aquí la Supervisión, como los tribunales de justicia-guardando las proporciones en sus consecuencias-, ejerció un control de carácter ideológico y de vigilancia a la disidencia al régimen en el sector educacional. Se intervinieron las escuelas y universidades con rectores delegados o interventores que vigilaban cuando se podría advertir un asomo de crítica y de organización.

\section{Evolución del sistema escolar y su impacto en la Supervisión Educativa}

El sistema educacional chileno, así como todo el sistema de administración pública, ha buscado y sigue haciéndolo, una mayor descentralización y, por ahora, solo ha logrado una mera desconcentración de funciones sin transferencias de poderes normalmente asociados al sistema financiero. En el caso que nos ocupa, el sistema escolar 
se caracteriza por disponer de proveedores mixtos, tanto públicos como privados con financiamiento público y particulares privados con financiamiento propio. Estos últimos son los únicos que gozan de una plena autonomía. Los tres tipos de proveedores con estudiantes de los tres niveles: infantil o preescolar, enseñanza básica y enseñanza media humanística y técnico-profesional. Para observar una evolución muy elocuente de la matrícula se puede observar el cuadro:

Cuadro i: Evolución de la matrícula por dependencia (\%)

\begin{tabular}{||c||c|c|c|}
\hline Dependencia & Particular & $\begin{array}{c}\text { Particular } \\
\text { pagado } \\
\text { subvencio- } \\
\text { nado }\end{array}$ & Municipal \\
\hline 1996 & 9,7 & 33,4 & 56,9 \\
\hline 2002 & 8,8 & 37,8 & 53,4 \\
\hline 2016 & 8 & 55,6 & 36,5 \\
\hline
\end{tabular}

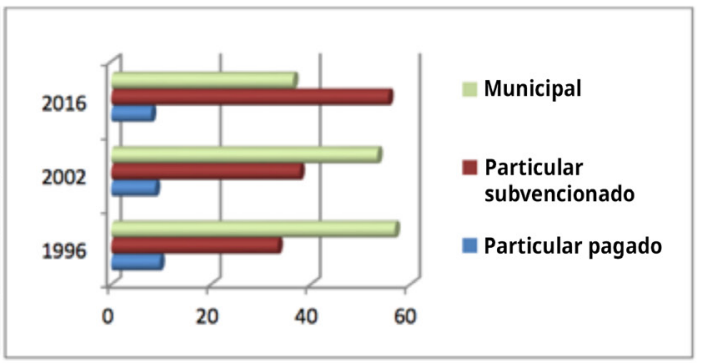

Fuente: Ministerio de Educación, Dirección de Planificación.

Como se observa la política instaurada desde los años ochenta prácticamente disminuye a la mínima expresión la participación de la educación pública a favor de un incremento de la educación particular subvencionada. Esta última consiste en un monto de dinero por estudiante que asiste a clases que recibe el sostenedor.

El sistema de supervisión chileno se crea formalmente a inicios de la década de los 80 , en su origen con una doble finalidad: fiscalizar, controlar e inspeccionar las subvenciones que entregaba el Estado a los sostenedores municipales y particulares resguardando la normativa que regulaba estas asignaciones; y, en segundo lugar, otorgar apoyo pedagógico y técnico a los colegios que los requieran. Hasta el día de hoy el primero siempre ha tenido mayor preeminencia que el segundo dadas sus tareas de control y atribución para aplicar multas o, incluso, llegar a la suspensión o cancelación del servicio educativo.

Para gestionar esto se crearon 40 Direcciones Provinciales de Educación (hoy, 20I8, existen 42) con dos unidades principales: la encargada de la Inspección Educativa son funcionarios denominados inspectores escolares que tenían por función fiscalizar el registro de matrícula y el registro escolar (libros de clases, rango etario de los estudiantes, escolaridad y el currículo vigente); por otro lado, la segunda unidad, que se denomina supervisión educativa, que reúne a profesionales de la educación que serán los encargados del apoyo pedagógico y técnico de los colegios en el ámbito de su jurisdicción, con una gama amplia y variada de roles y funciones.

Un segundo hito en la evolución del sistema de supervisión educativa se produce a partir de los años 90 con el advenimiento de la democracia en Chile. El rasgo cualitativo más relevante en esta etapa es la configuración de programas de intervención educativa, entre ellos los más destacados por inyección de cuantiosos recursos financieros e innovaciones pedagógicas en el sistema son: el Programa de las 900 Escuelas (P-900), peculiar iniciativa que fue financiada por el Gobierno de Suecia como donativo a las 900 escuelas más pobres del país. En adelante, los siguientes programas se 
denominarán del mismo modo con la sola diferencia de su ámbito específico de aplicación, así: Programa de Mejoramiento de la Equidad y Calidad de la Educación, en adelante Programa mecE: Pre Básica (o Educación Infantil); Programa mece Media, Programa MECE Rural, y, por extensión, continuó así a los programas MECE del sistema universitario superior, por más de una década. Estos programas fueron financiados con ingentes recursos por el Banco Mundial con préstamos a tasas preferenciales.

Todos estos programas modificaron la perspectiva de la supervisión como «proceso de apoyo externo a la unidad educativa, de carácter especializado, capaz de aportar al mejoramiento de los procesos técnico pedagógicos que se dan al interior de ella». Así, los propósitos de la supervisión fueron muy versátiles, como ejemplo, podemos mencionar algunos de ellos: asesorar el desarrollo del proyecto educativo (gestión escolar), apoyar al personal docente en el diseño de estrategias de enseñanza (didáctica), promover instancias de encuentro al interior de los establecimientos educacionales (gestión escolar/gestión de la convivencia), fomentar el análisis de las formas de evaluación de aprendizajes (gestión pedagógica), promover las relaciones entre escuelas y comunidad (gestión escolar), apoyar al cuerpo directivo en materias de administración escolar y estimular el desarrollo de instancias de participación en las escuelas (gestión escolar), entre otras. Queda claro que se ha ido dejando de lado, de forma paulatina y gradualmente, el asesoramiento a temas disciplinarios que era el sentido original de cómo se entendía el apoyo técnico-pedagógico.

El sistema nacional de supervisión estuvo y está estructurado hasta el día de hoy en tres niveles: nacional, regional y provincial.

El sistema nacional de supervisión. A cargo de la Coordinación Nacional de Supervisión (CNS), dependiente de la Dirección de Educación General (DEG), que es la unidad técnica y normativa responsable del desarrollo de los niveles de educación parvulario (infantil) o prebásica, básica, media con sus modalidades humanísticas y técnico-profesional. Esta macrounidad es la responsable de promover el mejoramiento permanente del proceso educativo formal y depende directamente del Ministerio de Educación.

Cabe señalar que la Coordinación Nacional de Supervisión (CNS) es una instancia centralizada a nivel ministerial porque es donde se elaboran las políticas y normativas que luego deben ser 'bajadas' a niveles locales en todo el país por medio de las unidades regionales y provinciales a las que aludiremos más adelante. La cNs tiene dos funciones centrales: orientar, coordinar y regular la organización y ejecución de la supervisión técnico-pedagógica en el territorio en los distintos niveles y modalidades educativas; y establecer normativas referidas a los aspectos técnico-pedagógicos del sistema escolar en su conjunto.

Finalmente, es a nivel nacional, central, donde la cNs coordina la planificación de acciones de supervisión requeridas por los programas de mejoramiento (recordar los programas MECE que hemos señalado más atrás) y de otras unidades ministeriales, de acuerdo a las metas establecidas por el Estado y el Gobierno de turno. Es la CNs quien elabora el Plan Anual de Supervisión (PAS), el cual 'debería' ser 'contextualizado' a nivel regional y provincial. El pas tiene como contenidos centrales: número de visitas a escuelas del territorio, talleres, jornadas de capacitación, encuentros, eventos, acciones de seguimiento, reuniones técnicas, entre muchas otras que incluyen encuentros concertados con autoridades locales e intermedias a fin de coordinar agendas y acuerdos de políticas y programas. Desde el año zoor se 
ha flexibilizado el mandato central a fin de contextualizar debidamente el pAs a las necesidades locales.

A nivel regional, la unidad se denomina Secretaría Regional Ministerial de Educación (SECREDUC) y reproduce la estructura y el modelo organizativo del nivel central. Así, esta unidad se estructura en departamentos, de los cuales uno muy relevante es el Departamento de Educación y que lo coordina un jefe de Área y otros departamentos según niveles y modalidades de enseñanza, de acuerdo a la naturaleza regional. En particular, el Departamento de Educación tiene como función contextualizar el pas nacional a nivel regional con criterios técnicos-pedagógicos y que serán desarrollados en el periodo respectivo. Así, las principales funciones en orden a la supervisión que debe desempeñar la SECREDUC son la planificación y el diseño en conjunto con el nivel provincial de las acciones supervisoras de acuerdo a las metas nacionales, los diagnósticos y planes regionales; evaluación del PAs regional en función de ambos parámetros (nacional y regional) en orden a la supervisión regional y provincial; finalmente, una función de asesoría centrada en la elaboración, seguimiento y evaluación de programas y proyectos de mejoramiento de la calidad de la educación, instrumentos de supervisión, modelos de supervisión con apoyo a través de alianzas estratégicas con universidades, centros de investigación y de organizaciones funcionales, por ejemplo, municipios que, por agregar y un dato relevante, hasta 2018 es uno de los principales sostenedores de la educación de carácter público.

A nivel provincial, la supervisión tiene como finalidad el apoyo al mejoramiento de la calidad de la educación, con énfasis en los procesos técnicos y pedagógicos que se desarrollan en los colegios, en particular, los colegios focalizados, esto es, aquellos que han tenido promedios de desempeño más exiguos. La unidad que se encarga de este trabajo territorial a nivel local se denomina Departamento Provincial de Educación (DEPROv), en ella existen dos jefaturas: el jefe provincial de Educación del DEPROv, propiamente tal, y el jefe técnico de Supervisión. A su cargo están los jefes de los distintos niveles de enseñanza y modalidades, así como de programas especiales, tales como interculturalidad, educación especial, de adultos, etc. Las funciones específicas de esta unidad son: evaluar los avances de la reforma educacional a nivel de colegios, los avances de los diversos procesos técnico-pedagógicos y, finalmente, el PAS a nivel provincial.

En la actualidad existen alrededor de 600 supervisores distribuidos en las 42 provincias, a diferencia del inicio del sistema donde el perfil profesional exigía que todos ellos fueran docentes, hoy hay una gran variedad de profesionales de distintos orígenes disciplinarios, entre ellos, ingenieros civiles, ingenieros comerciales, sociólogos, psicólogos, trabajadores sociales, economistas, abogados, no obstante, siguen prevaleciendo los educadores por la índole específica de la tarea. Lo anterior es interesante porque se abren las expectativas de los aportes que los profesionales pueden hacer al sistema educativo en general y al escolar en particular, ciertamente, hay una mirada más sistémica y multidisciplinaria.

Un Informe de la OCDE (1998) señala una conclusión muy preocupante: el vínculo entre la supervisión y las escuelas es débil, de lo cual puede inferirse que estas, incluidos profesores y directivos, se encuentran sin apoyo técnico-pedagógico, esto es, distanciados de la supervisión educativa; diferenciándose de los inspectores de subvenciones, aquel funcionario que controla y fiscaliza la matrícula y la cuestión financiera en las escuelas. Este informe obligó a la cNs a elaborar un diagnóstico completo del sistema nacional de supervisión. 
Este diagnóstico del sistema se realizó para el trienio 2000 a 2003 y arrojó las siguientes y preocupantes conclusiones:

- El sistema de supervisión aparece con bajas competencias y falta de autoridad técnica y con baja legitimidad.

- En las escuelas hay bajo liderazgo técnico de docentes y directivos para orientar su desempeño concreto en las distintas áreas.

- Los sostenedores, quienes gestionan los recursos económicos de la escuela, tampoco han recibido orientación y formación para ejercer su cargo en orden a las orientaciones generales del país, cuestión que es lo más preocupante respecto de todos los actores.

- Como consecuencia de lo anterior, tampoco hay un acuerdo básico general respecto del rumbo de la educación y ello es atribuible a ese bajo vínculo entre el Estado y las escuelas, es decir, entre la supervisión y los actores educativos.

- Otra conclusión preocupante es aquella que señala que no hay concordancia ente la oferta del Ministerio de Educación y las demandas propias -endógenasde la escuela y sus actores. Esto impacta al Plan Anual de Supervisión (PAs) tanto nacional como regional y provincial, lo cual es preocupante, pues es la carta de navegación de los supervisores del país que tendería a ser -en la época referida- descontextualizada.

- Señala el documento que los supervisores no tienen criterios claros y precisos de actuación en su desempeño en las escuelas, por lo tanto, hay una dispersión en la orientación de políticas desde el Estado.

- No hay, en esa fecha, un sistema de monitoreo y seguimiento que acompañe a los supervisores para su reciclaje y renovación de sus prácticas supervisoras.

- Advierte débil liderazgo técnico de los jefes provinciales en el ámbito de su desempeño.

- Termina la oCDE señalando que falta una articulación de la oferta ministerial y del Estado en general respecto de las necesidades de la escuela y sus actores.

Las conclusiones anteriores de un organismo neutro como es la OCDE, sumado a este diagnóstico, fueron muy preocupantes de tal forma que la CNS abrió desde $200 \mathrm{I}$ y 2002 un proceso amplio de reforma y modernización que buscó transformar la supervisión en un dispositivo estratégico, lo cual supone entender al supervisor como agente de calidad del Ministerio de Educación que permita trabajar coordinadamente la política educativa ministerial en todo el territorio y una 'bajada' de las reformas en todas las áreas de innovación pedagógica, curricular, docente y directivo. Esto va a 'interpelar' a los equipos provinciales y regionales de supervisores forzándolos a sintonizar con las demandas de las escuelas y sus actores y conectarlas con las propuestas ministeriales, es decir, una relación bidireccional que rompería con el clásico centralismo. Alrededor del 2015 ya la cNS pasa a denominarse Unidad de Apoyo a la Mejora, lo cual refleja también una tendencia a un giro paradigmático.

El paradigma del 2000 es, y subsiste hasta hoy (2018), está radicado en la calidad de los aprendizajes y cómo sinérgicamente toda la política contribuye a ello; se crean proyectos y programas contributivos a dicho propósito: el Sistema de Aseguramiento de la Calidad y de la Gestión Escolar (SACGE), que busca potenciar la gestión directiva por medio de diagnósticos participativos y levantamiento de propuesta de mejora consensuada por los actores de la comunidad escolar. Por otro lado, están la elaboración 
de estándares de calidad tanto de la gestión como de la docencia como parámetros de calidad. Esto se traduce en el consenso de competencias y dominios de responsabilidad para todos los actores del sistema educativo: profesores, directivos, estudiantes, etc.). Una tercera iniciativa ha sido renovar la oferta ministerial por medio de acoger las demandas locales mediante la coparticipación en la elaboración del pas respecto de la agenda de la supervisión. Posteriormente, saldrán nuevas orientaciones que han causado mucho impacto, por ejemplo, el Marco de la Buena Enseñanza (MBE, 2008) y el Marco de la Buena Dirección (MBD, 2005), ambos en la actualidad documentos orientadores, no prescriptivos, con versiones renovadas al 2015 , como se ilustra en la siguiente imagen continuación:

Imagen I: Respecto del Marco Buena Dirección y Liderazgo Escolar (MBDLE, 20I5)
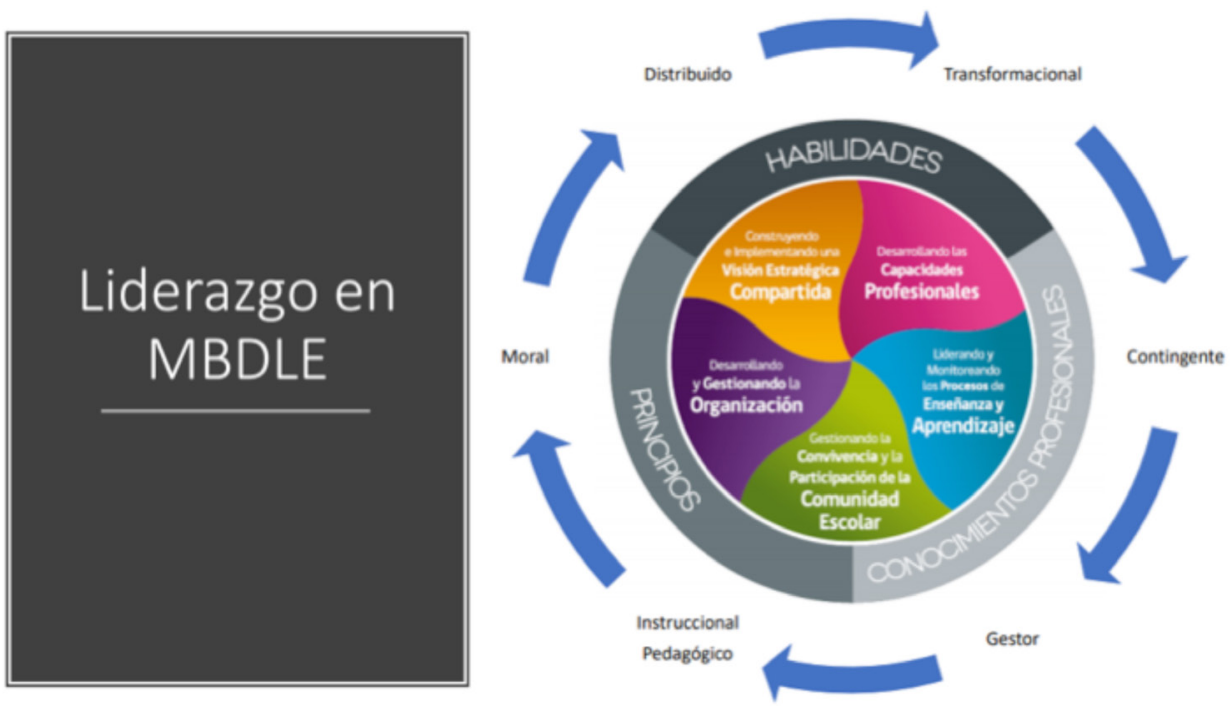

Fuente: Ministerio de Educación, 2015.

El Marco de la Buena Dirección 2005 (MBD) presenta cuatro pilares fundamentales: liderazgo, gestión del currículo, gestión de recursos y gestión del clima organizacional y convivencia escolar. Este marco de referencia estuvo más centrado en el desarrollo de competencias directivas y el actual que refleja la ilustración de más arriba tiende al desarrollo de capacidades y habilidades e incluye aspectos éticos y actitudinales; podríamos señalar que el actual (Ministerio de Educación, 2015) es más completo, además, porque incluye prácticas de los directivos.

Desde luego hay tópicas cuestiones discursivas en todo esto, pero claramente demuestra una nueva tendencia y orientaciones paradigmáticas que contribuyen a redefinir la tarea y el rol específico de la supervisión en Chile en el nuevo siglo. Es lo que abordaremos en esta última fase que alude al presente estadio de la supervisión en Chile y las nuevas directivas desde el Ministerio de Educación, en particular desde la Dirección de Educación General y la Unidad de Apoyo a la Mejora (ex CNs). 
Seguimos aquí a Gonzalo Muñoz Stuardo, exjefe de la Dirección de Educación General (DEG), cuando señala con mucho acierto que «la educación chilena vive un momento histórico: tiempo de reflexión, de diálogo y de cambio de paradigma. [...] La Reforma consiste en impulsar un proceso de mejoramiento educativo integral, en el que cada una de las comunidades escolares está llamada a ser protagonista» (Muñoz, 2015: 6).

Ciertamente, en esta última fase, década del 2oro, se está exigiendo al sistema el desarrollo e instalación de capacidades en las escuelas a fin de generar mayor autonomía en la toma de decisiones a nivel local. Hay dos instrumentos que promueve el MINEDUC para alcanzar esa meta: los Proyectos Educativos Institucionales (PEI) y los Planes de Mejoramiento Educativo (PME), ambos exigidos por senda leyes: Ley General de Educación (LGE, diciembre, 2009) y la Ley de Subvención Escolar (Ley SEP, abril, 20I2). Son centrales pues ambos exigen levantar auto-diagnósticos institucionales con participación de todos los actores concernidos: directivos, docentes, asistentes de la educación, estudiantes, padres y apoderados y comunidad en general. Mientras haya participación mayor es la adhesión y compromiso con los proyectos. En este contexto la participación de los supervisores es clave y se releva más, pues son ellos quienes deberían movilizar los recursos del Estado para asesorar proyectos que, además de incorporar las necesidades locales, alinean los proyectos con la política educativa.

Este es uno de los desafíos, pero no el único, pues con la nueva legislación se generó un nuevo esquema de la educación pública, representado en la siguiente imagen:

Imagen II: Nueva Educación Pública

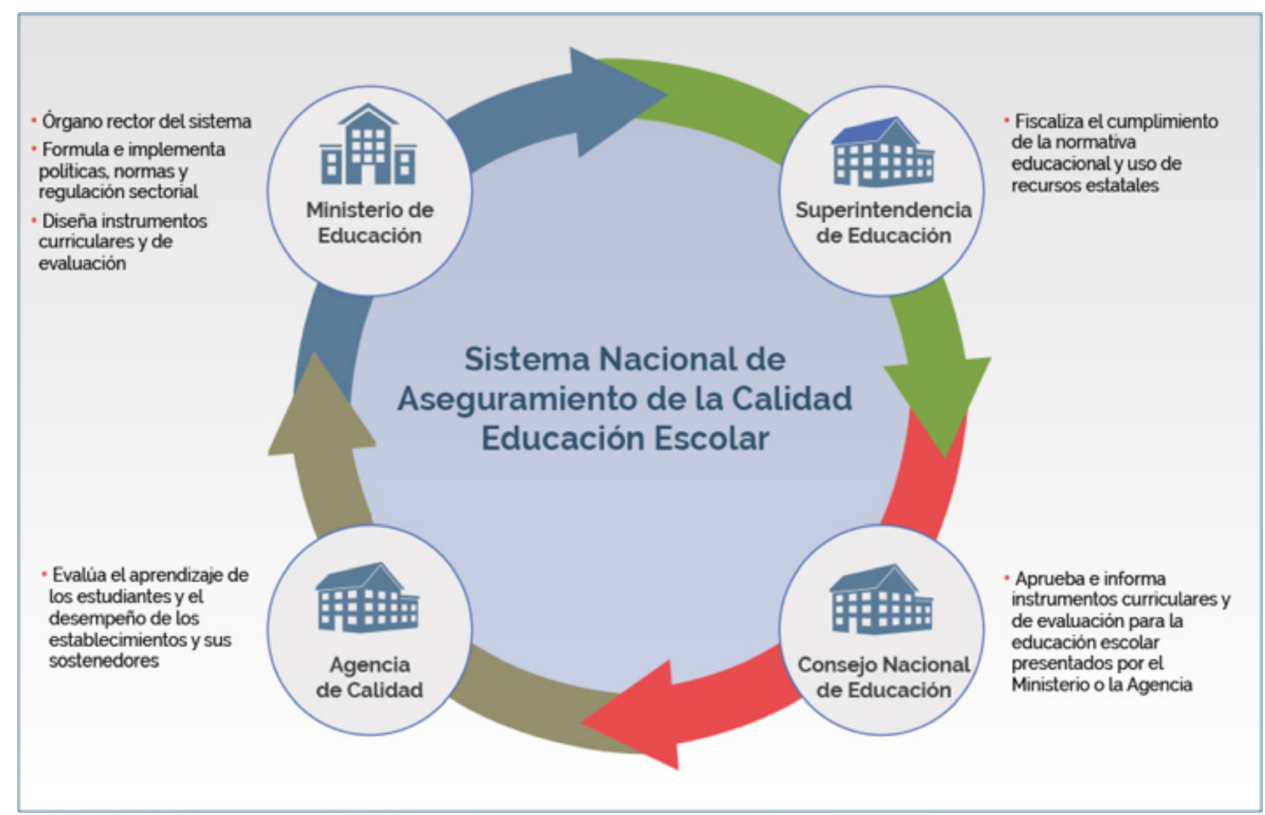

Fuente: Ministerio de Educación, 20I5. 
De acuerdo al nuevo panorama, el supervisor está radicado en el órgano rector del nuevo sistema: el Ministerio de Educación, pero está acompañado de tres instituciones muy poderosas: la Superintendencia de Educación, el Consejo Nacional de Educación y la Agencia de Calidad, cada uno con sus roles y funciones muy definidas por ley, no obstante dos de ellas también deben visitar los colegios y ello debe coordinarse y articularse muy bien para que no represente una sobreexigencia a nivel directivo, pues ya en 2018 se ha instalado una discusión pública en orden a que los equipos directivos deben asumir entre 180 y 230 tareas burocrático-administrativas (papeles) que tiene que ver necesariamente con aquello que la sociedad está esperando de ellos: que se ocupen de generar las condiciones necesarias para mejorar la calidad de los aprendizajes de los estudiantes y disminuir las brechas de desigualdad en la distribución del conocimiento.

\section{Bibliografía}

BANDURA, A. (1999) Ejercicio de la eficacia personal y colectiva en sociedades cambiantes. En A. Bandura (coord.) Autoeficacia: Cómo afrontamos los cambios de la sociedad actual. Bilbao: Desclée de Brouver.

Barber, M. y Mourshed, M. (2008) Cómo hicieron los sistemas educativos con mejor desempeño del mundo para alcanzar sus objetivos (vol. 4I). PREAL.

Bellei, C.; Valenzuela, J.; Vanni, X. y Contreras, D. (20I4) Lo Aprendí en la Escuela: ¿Cómo se logran procesos de mejoramiento escolar? Santiago, Chile: LOM.

Bolívar, A. (1997) Liderazgo, mejora y centros educativos. En A. Medina (coord.) El liderazgo en educación (pp. 25-46). Madrid: UNED.

Bolívar, A. (20Io) El liderazgo educativo y su papel en la mejora: Una revisión actual de sus posibilidades y limitaciones. Psicoperspectivas, 9 (2), 9-33. www. psicoperspectivas.cl.

Carbone, R. (2008) Situación de liderazgo educativo en Chile. Santiago: Ministerio de Educación, Universidad Alberto Hurtado.

cide, Universidad Alberto Hurtado (2014) Desarrollo de Estándares de Directores Escolares y la Medición de la Brecha existente entre las Prácticas y Habilidades Directivas actuales $y$ las definidas en los Estándares. Informe Final.

Elmore, Richard (2010) Mejorando la Escuela desde la Sala de clases. Serie Liderazgo Educativo. Fundación Chile, Santiago, 63.

Garay, S. (2008) Modelo de liderazgo para una dirección efectiva. En O. Maureira (ed.) Perspectivas de gestión para la innovación y el cambio educativo (pp. 135-184). Santiago: Ediciones UCSH.

Goleman, D. (2013) Liderazgo: El poder de la Inteligencia emocional. Madrid: Ediciones B.

González García, G. (2005) La supervisión pedagógica pública en Chile. Un análisis de la gestión del supervisor como promotor del cambio educativo y mejoramiento en las escuelas. REICE. Revista Iberoamericana sobre Calidad, Eficacia y Cambio en Educación, 3 (I), 629-636.

Hargreaves, A. y Fullan, M. (20I4) Capital profesional: transformar la enseñanza en cada escuela. Madrid: Morata.

Horn, A. y MARfán, J. (20IO) Relación entre liderazgo educativo y desempeño escolar: Revisión de la investigación en Chile. Psicoperspectivas. Individuo y Sociedad, vol. 9, 2.

Kotter, J. P. (2002) Lo que de verdad hacen los líderes. Harvard Business Review - Liderazgo. Editorial Universidad de Deusto.

Leithwood, K. (2009) ¿Cómo Liderar nuestras Escuelas? Aportes desde la Investigación. Santiago: Fundación Chile, Área Educación. 
Marfán, J.; Muñoz, G. y Weinstein, J. (20I2) Liderazgo directivo y prácticas docentes: Evidencia a partir del caso chileno. Organización y gestión educativa: Revista del Fórum Europeo de Administradores de la Educación, vol. 20, 3, 19-24.

Ministerio de Educación de Chile (2005) Marco para la Buena Dirección. Criterios para el Desarrollo profesional y Evaluación del Desempeño. http://www.mineduc.cl/usuarios/ convivencia_escolar/doc/201103070I55490. MINEDUC.Marco_para_la_Buena_Direccion.pdf.

Ministerio de Educación del Perú (2014) Marco de Buen Desempeño del Directivo: Directivos construyendo escuela.

Mistral, G. (1923) Pensamientos Pedagógicos. Revista Educación, año II, i en Magisterio y Niño, 39. http://www.memoriachilena.cl/archivos2/pdfs/MCooı0808.pdf.

Muñoz, G. (2015) Orientaciones para el apoyo técnico pedagógico al sistema escolar. División de Educación General, Ministerio de Educación. http://www.textosescolares.cl/usuarios/ convivencia_escolar/doc/20I503031621270.Orientaciones\% 20para\% 20el\% 20apoyo\% 20tecnico\% 2opedagogico.pdf.

Muñoz, G. y MARFÁn, J. (2OII) Formación y Entrenamiento de los directores escolares en Chile: Situación actual, desafíos y propuestas de política. Fondo Nacional de Innovación y Desarrollo en Educación. Ministerio de Educación.

OECD (2017) Education in Chile, Reviews of National Policies for Education, Paris: OECD Publishing, https://doi.org/I0.1787/9789264284425-en.

Rincón-Gallardo, S. y Fullan, M. (2016) La Física Social del Cambio Educativo: Características Esenciales de la Colaboración Eficaz. Traducción al español de borrador entregado para el número inaugural del Journal of Professional Capital and Community, a publicarse en 20I6. Presentado en Chile en el Seminario de la «Red de Escuelas Líderes», julio 2015.

Sebring, P. B. y Montgomery, N. (20I4) Los cinco apoyos esenciales para el mejoramiento de los aprendizajes en la escuela: movilizando los resultados. Pensamiento Educativo-PUC. Revista de Investigación Educacional Latinoamericana, 5I (I), 63-85.

Uribe, M. (20Io) Profesionalizar la Dirección Escolar Potenciando el Liderazgo: Una Clave Ineludible en la Mejora Escolar. Desarrollo de Perfiles de Competencias Directivas en el Sistema Educativo Chileno. Revista Iberoamericana de Evaluación Educativa, 3 (Iе), 303-322.

URIBE, M. y Celis, M. (20I2) Desarrollo de capacidades para un liderazgo escolar efectivo: del levantamiento de competencias al reconocimiento de buenas prácticas. En ¿Qué sabemos de los directores de Escuela en Chile? Weinstein, J. y Muñoz, G. Editores.

Valenzuela, P. y Horn, A. (2012) Influencia del liderazgo directivo en los resultados de los estudiantes. En ¿Qué sabemos sobre los directores de escuela en Chile? 325-348.

Volante, P. (20I2) Liderazgo instruccional y logro académico en la educación secundaria en Chile. En ¿Qué sabemos sobre los directores de escuela en Chile?, 349-370.

Weinstein, J. et al. (2009) Prácticas de liderazgo directivo y resultados de aprendizaje. Hacia conceptos capaces de guiar la investigación empírica. Revista Iberoamericana sobre Calidad, Eficacia y Cambio en Educación, 7 (3), 20-33.

Weinstein, J. y Muñoz, G. (2012) ¿Qué sabemos de los directores de escuela en Chile? Ed. CEPPE y Centro de Innovación en Educación Fundación Chile.

Weinstein, J.; Muñoz, G. y Marfán, J. (20I2) ¿Colegas y Jefes?: La visión de los docentes sobre el Liderazgo Directivo en Chile. En ¿Qué sabemos sobre los directores de escuela en Chile? 255-282. 